Association for Information Systems

AIS Electronic Library (AISeL)

6-15-2020

\title{
RECONCEPTUALISING BUSINESS-IT ALIGNMENT FOR ENABLING ORGANISATIONAL AGILITY
}

\author{
Bettina Horlach \\ University of Hamburg, horlach@informatik.uni-hamburg.de \\ Paul Drews \\ Leuphana University of Lüneburg, paul.drews@leuphana.de \\ Andreas Drechsler \\ Victoria University of Wellington, andreas.drechsler@vuw.ac.nz \\ Ingrid Schirmer \\ University of Hamburg, schirmer@informatik.uni-hamburg.de \\ Tilo Böhmann \\ Universität Hamburg, tilo.boehmann@uni-hamburg.de
}

Follow this and additional works at: https://aisel.aisnet.org/ecis2020_rp

\section{Recommended Citation}

Horlach, Bettina; Drews, Paul; Drechsler, Andreas; Schirmer, Ingrid; and Böhmann, Tilo, "RECONCEPTUALISING BUSINESS-IT ALIGNMENT FOR ENABLING ORGANISATIONAL AGILITY" (2020). ECIS 2020 Research Papers. 95.

https://aisel.aisnet.org/ecis2020_rp/95

This material is brought to you by the ECIS 2020 Proceedings at AIS Electronic Library (AISeL). It has been accepted for inclusion in ECIS 2020 Research Papers by an authorized administrator of AIS Electronic Library (AISeL). For more information, please contact elibrary@aisnet.org. 


\title{
RECONCEPTUALISING BUSINESS-IT ALIGNMENT FOR ENABLING ORGANISATIONAL AGILITY
}

\author{
Research paper \\ Horlach, Bettina, University of Hamburg, Hamburg, Germany, horlach@informatik.uni- \\ hamburg.de \\ Drews, Paul, Leuphana University Lüneburg, Lüneburg, Germany, paul.drews@leuphana.de \\ Drechsler, Andreas, Victoria University of Wellington, Wellington, New Zealand, \\ andreas.drechsler@vuw.ac.nz \\ Schirmer, Ingrid, University of Hamburg, Hamburg, Germany, schirmer@informatik.uni- \\ hamburg.de \\ Böhmann, Tilo, University of Hamburg, Hamburg, Germany, tilo.boehmann@uni- \\ hamburg.de
}

\begin{abstract}
Organisations increasingly strive to increase their ability to proactively sense and respond to market opportunities and threats to remain competitive by embracing organisational agility. As doing so often blurs traditional boundaries between business and IT, this has considerable implications for the business-IT alignment (BITA) concept. Based on empirical data from focus groups and interviews with 36 practitioners from multiple positions and industries, we identify four organisational challenges for BITA in agile contexts: 1) to establish an effective focus on the business environment, 2) to balance the autonomy of single teams for decision-making concerning the development and use of IT 3) and service functionalities with the organisation-wide optimum, and 4) coping with the fluidity of the organisation's structure and processes. We subsequently derive four design goals and five design principles to address these challenges. In addition, we contribute to research by reconceptualising BITA for agile contexts. Organisations can draw on our findings to guide their agile transformation journeys.
\end{abstract}

Keywords: Agility, Business-IT Alignment, BITA, Architectural Alignment

\section{Introduction}

The digital age with its hyper-competition and volatile business environments deeply challenges established companies. Power shifts to the customer who can select a preferred service from a vast array of possibilities (Denning, 2010; Denning, 2016). Consequently, companies more than ever strive for being able to always provide the 'right' customer services, often accompanied by a required timeliness in delivery (Overby et al., 2006; Lee et al., 2015). This dynamic calls for corresponding organisational responses to foster and improve their ability in being proactive in sensing the needs and responding with speed and dexterity to fulfil and surpass customers' expectations (e.g. Sambamurthy et al., 2003) - or in other words, to embark on a transformational journey to increase organisational agility.

While literature on the understanding of business-IT alignment (BITA) in traditional IT environments is extensive and mature, the agility debate is rather disconnected from alignment research. Although evidence shows that at least a high degree of social alignment facilitates agility (Tallon, 2008; Tallon \& Pinsonneault, 2011; Liang et al., 2017), paths on how to achieve this form of alignment in detail are yet scarce. Existing approaches on how to integrate agility within the organisation also provide limited insights on implications for BITA, as most approaches primarily focus on the acceleration and optimisation of the IT delivery despite agility increasingly being perceived as an enterprise-wide concern. 
Firstly, operational approaches lack an enterprise-wide perspective. Scrum (Schwaber and Sutherland, 2019) or self-organising IT teams show the merge of IT development with IT operations via DevOps (Kim et al., 2016) on the team-level, and thus lack a holistic agility perspective that also includes the business side. Frameworks for bimodal IT (Haffke et al., 2017a,b; Horlach, 2017) or large scale agile transformations of the whole (IT) organisation (Scaled Agile, 2019; Disciplined Agile, 2019) try to include an organization-wide perspective, but limit themselves primarily to scaling agile in the IT side.

Thus, concrete recommendations for agile organisations on how to integrate their business with their IT and underlying rationales remain an area of research. This integration, however, is highly relevant as digital innovation deeply intertwines IT and business logic (Melarkode et al., 2004) and fusionfocused constructs like digital business strategies are proclaimed as essential for shaping a responsive organisation (Bharadwaj et al., 2013; Kahre et al., 2017). Therefore, more specific recommendations are needed on how to achieve effective agile transformations that retain and improve BITA. Moreover, since agile transformations commonly blur traditional distinctions between business and IT, the question arises how to adapt the BITA concept itself. Thus, we seek to answer the following questions:

\section{RQ1: What BITA-related challenges do organisations face in their agile transformations?}

RQ2: How can organisations address these challenges effectively?

RQ3: How is BITA to be reconceptualised for agile organisations?

To provide our answers, we draw on data collected in two phases comprising focus groups and expert interviews with CIOs, CDOs, and further roles from multiple organisational levels as well as external consultants in the area of enterprise-level agility. To answer RQ1 and RQ2, we then derive challenges, design goals, and design principles for alignment in agile organisational contexts by conducting an abductive qualitative analysis. In this analysis, we employ theory-inductive coding informed by BITA and agility research and additional open coding inspired by the grounded theory approach (Strauss and Corbin, 1991) in order to not miss out on important aspects based on a narrow theoretical perspective. To answer RQ3, we then take a step beyond the identified challenges, goals, and principles and develop a conceptual model for BITA in agile organisational contexts.

\section{Research Background}

As business organisations have become very dependent on IT services to achieve their goals, the synchronisation of those entities, commonly known as business-IT alignment or BITA, is regarded as a key issue for business and IT executives and managers (Gerow et al., 2014; Luftman et al., 2017). BITA is of a complex character, as it involves multiple dimensions (Chan and Reich, 2007; Ullah and Lai, 2013). First, there is the strategic or intellectual dimension, as the business and IT strategy and plans must be understood by both business and IT (King, 1978; Lederer and Mendelow, 1989) and need to be in agreement (Kearns and Lederer, 2000). Second, approaches such as the Strategic Alignment Model (SAM) by Henderson and Venkatraman (1993) also call for a fit and close links between business and IT on the structural level, which include decision-making rights, (de)centralisation of IT, or IT personnel deployment (Chan and Reich, 2007; Chan, 2002). The third dimension is the social dimension. A shared understanding of business and IT professionals and enabling trust between the two functions (Broadbent and Weill, 1993; Kashanchi and Toland, 2008) is seen as a baseline for committing IT support for the business strategy and vice versa (Haki and Forte, 2010) and the commitment to each other's plans, objectives, and mission (Reich and Benbasat, 2000). Fourth, social alignment is closely linked to the cultural fit (Luftman et al., 1999) with its planning and communication styles (Pyburn, 1983; Chan, 2002) for sustaining successful communication between both groups (Van de Zen and Jong, 1999). Thus, despite the variety along the dimensions, business IT alignment can be characterized as orchestrating the separate entities of business and IT to have them work together towards a common (business) goal (Luftman et al., 1999; Henderson and Venkatraman, 1993).

In the agility literature, BITA is covered rather implicitly as an influencing factor (Tallon, 2008). According to the Agile Manifesto (Beck et al., 2001), agility on the team level emphasises close collaboration between the business (as the customer) and the agile team. In more recent times, BizDevOps 
proposed to increase the autonomy of the agile team by having parts of the business as customer within a team (Fitzgerald and Stol, 2017). However, agility as the ability for sensing changes in the environment (Sambamurthy et al., 2003; Lu and Ramamuthy, 2011) and reacting with dexterity, speed, and innovation (Liang et al., 2017; Roberts and Grover, 2012; Conboy and Fitzgerald, 2004) increasingly advances beyond a single team perspective. An example is the rise of bimodal IT and the resulting establishment of digital units for faster delivery of digital services with multiple agile teams. This results in a debate on how to enable organisational agility while ensuring cross-team alignment (Kniberg and Ivarsson, 2012; LeSS Company, 2019; Moe et al., 2019) through communities of practice (Paasivaara and Lassenius, 2014) or common principles (Faraj \& Xiao, 2006). The communication capabilities (Roberts and Grover, 2012; Fink and Neumann, 2007) shall also span business and IT, as both business and IT logics are intertwined in digital service provision based on direct customer insights (Melarkode et al., 2004; Bharadwaj et al., 2013; Kahre et al., 2017). A similar evolution is seen in the second popular direction of large scale agile, which positions agility as an enterprise-wide concern. An increasing number of frameworks providing blueprints for agility on the organisational level (e.g. Scaled Agile, 2019; Disciplined Agile, 2019) emphasise that practices for coordination across the enterprise such as cross-unit business and IT roles (Scaled Agile, 2019; van Oosterhout, 2006) or a central portfolio management (Laanti, 2008; Hoffmann, 2017; Horlach et al., 2019) need to exist to achieve alignment and agility simultaneously (Bradley et al., 2012; Tiwana and Konsynski, 2010).

However, as most approaches limit scaling the agile context to the IT organisation (Scaled Agile, 2019; XSCALE, 2019) despite BITA being an enterprise-wide concern, alignment is not explicitly addressed regarding its concrete involvement (Disciplined Agile, 2019). Instead, BITA is often only emphasised as a goal, similar to the debate on the unit level. Only some authors target the direct link between alignment and agility (Tallon, 2008; Tallon \& Pinsonneault, 2011; Liang et al., 2017). These authors emphasise that social alignment in particular does positively influence agility, while a high degree of intellectual alignment may lead to inertia and myopia, as business and IT executives tend to focus on internal concerns while losing the external perspective concerning the fit between the changing environments and the internal strategy and delivery. These authors call for IT to be embedded in key business processes (Denning, 2017a,b) for collaborative decision-making (He and Wong, 2004). Dynamic alignment (Vessey and Ward, 2013; Sushil, 2015) with dynamic decision-making (Smith, 2014; Doz and Kosonen, 2010; Tiwana and Kim, 2015) shall manifest the shared understanding between business and IT executives to recognise changes and be able to react rapidly.

However, it is still unclear how organisations could establish effective BITA in the most favourable way in their agile journeys. The existing blueprints are of not much help in this regard, as most of their advice is too specific to account for the diversity of existing organisational contexts. Thus, analyses and mechanisms for answering these calls by strategic and structural practices is yet in its nascence. The same applies to the cultural dimension of alignment, although the culture is seen as key for the ability of mobilisation of core capabilities, knowledge, and processes (e.g. Lee et al., 2015; Goldman et al., 1995). Yet, as BITA naturally becomes a focal point during agile journeys, answers are required on how is it to be shaped for companies to enable agility's dimensions of sense and response.

\section{$3 \quad$ Research Methodology}

To inform our BITA reconceptualisation for agile contexts and to give companies actionable guidance, we follow a duality of knowledge goals. To capture effective prescriptive knowledge by design theorizing to produce pre-artefact and pre-design-theory design knowledge (Weick, 1995; Baskerville et al., 2015), we first identify challenges that organisations face on their agile journey and then derive design goals and principles based on the obstacles, following the guidance by Gregor and Jones (2007) and Drechsler and Hevner (2018). Design goals and principles are perceived as abstract yet desirable knowledge for design or action (Kuechler and Vaishnavi, 2008), as giving more specific advice ('instantiating' the abstract design principles for specific companies) would require tailoring to the respective corporate contexts (Drechsler and Hevner, 2018). Second, we generalise and conceptualise our gained understanding in form of the reconceptualised BITA model which captures observed and gen- 
eralised patterns with respect to the alignment concept in the new context of agility. This model represents pre-theoretical knowledge as a result of theorizing (Weick, 1995) or sense-making (Drechsler and Hevner, 2018) of the findings. The findings are based on insights from a two-phase cross-industry qualitative study with 36 participants from various organisational contexts (see Table 1).

\begin{tabular}{|c|c|c|c|c|c|}
\hline & Interview & Position & Main Industry Affiliation & Size (in '000 pers.) & Setting \\
\hline \multirow{7}{*}{ 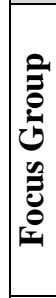 } & FG1 & $\mathrm{CIO}$ & Banking & $50-100$ & Face to face \\
\hline & FG2 & $\mathrm{CIO}$ & Utilities & $5-25$ & Face to face \\
\hline & FG3 & $\mathrm{CIO}$ & Insurance & $0-5$ & Face to face \\
\hline & FG4 & $\mathrm{CIO}$ & Insurance & $0-5$ & Face to face \\
\hline & FG5 & $\mathrm{CIO}$ & Retail & $50-100$ & Face to face \\
\hline & FG6 & $\mathrm{CDO}$ & Government & $5-25$ & Face to face \\
\hline & FG7 & CDO & Utilities & $0-5$ & Face to face \\
\hline \multirow{16}{*}{ 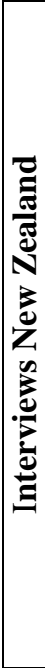 } & I1 & Program Manager & Telco & $5-25$ & Face to face \\
\hline & $\mathrm{I} 2$ & Program Manager & Telco & $5-25$ & Face to face \\
\hline & I3 & Chief Product Owner & Telco & $5-25$ & Face to face \\
\hline & I4 & Enterprise Architect & Banking & $0-5$ & Face to face \\
\hline & I5 & Enterprise Architect & Banking & $0-5$ & Video call \\
\hline & I6 & PMO & Energy & $5-25$ & Video call \\
\hline & I7 & PMO & Government & $0-5$ & Face to face \\
\hline & I8 & CEO Tool Vendor 1 & Transport, Energy, Health & Diverse & Face to face \\
\hline & I9 & CEO Tool Vendor 2 & Banking, Government & Diverse & Face to face \\
\hline & $\mathrm{I} 10$ & CEO Tool Vendor 3 & Insurance, Energy, Telco & Diverse & Video call \\
\hline & I11 & Consultant & Telco, Government, Banking & Diverse & Face to face \\
\hline & $\mathrm{I} 12$ & Consultant & NGO, IT, Banking & Diverse & Face to face \\
\hline & I13 & Consultant & Energy, Banking & Diverse & Face to face \\
\hline & I14 & Consultant & Government, Banking, IT & Diverse & Face to face \\
\hline & I15 & Consultant & Insurance, Government, Utilities & Diverse & Face to face \\
\hline & I16 & Consultant & Utilities, IT, Retail & Diverse & Face to face \\
\hline \multirow{13}{*}{ 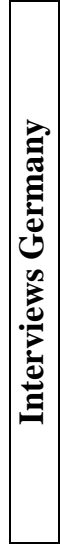 } & I17 & Product Owner & Retail & $50-100$ & Face to face \\
\hline & I18 & Product Owner & Retail & $0-5$ & Face to face \\
\hline & I19 & Team Architect & Retail & $50-100$ & Face to face \\
\hline & I20 & Enterprise Architect & Retail & $50-100$ & Face to face \\
\hline & I21 & Enterprise Architect & Retail & $25-50$ & Telephone call \\
\hline & $\mathrm{I} 22$ & PMO & Utilities & $0-5$ & Telephone call \\
\hline & I23 & Chief Product Owner & \begin{tabular}{|c|} 
Retail \\
\end{tabular} & $50-100$ & Face to face \\
\hline & I24 & Consultant & Automotive, Insurance, Banking & Diverse & Telephone call \\
\hline & I25 & Consultant & \begin{tabular}{|c|} 
IT, Retail \\
\end{tabular} & Diverse & Telephone call \\
\hline & I26 & Consultant & Retail, Automotive & Diverse & Telephone call \\
\hline & I27 & Consultant & IT, Retail & Diverse & Telephone call \\
\hline & I28 & Consultant & Retail, Banking & Diverse & Telephone call \\
\hline & $\mathrm{I} 29$ & Consultant & Automotive, Banking & Diverse & Face to face \\
\hline
\end{tabular}

Table 1. $\quad$ Participants in the empirical study.

The first data collection phase encompassed a cross-industry study with IT executives (CIO or CDO) in a single country from seven public and private organisations. The participants were identified by the following criteria: 1) their organisation is undergoing a transformation towards organisational agility that is reshaping both (parts of) business and IT, 2) they hold a position with in-depth insights on the overall organisational system, and 3) they are willing to partake in open information sharing among the researchers and the companies. For understanding the individual agile transformation efforts, we first conducted a single semi-structured interview with each participant. Each interview session took ca. 60 minutes and was audio-recorded and transcribed. To gather further details on the agile transformations and deriving patterns based on comparison, we conducted three single day focus group workshops (Krueger and Casey, 2014) with the same participants in spring and summer of 2018 and in 
winter of 2019. In multiple sessions, the participants discussed the nature of their decision-making and coordination, the reasons for their approach, and the consequences for their organisational setup.

The second phase involved a cross-industry study with 22 participants across two countries for gaining broader perspectives on agility's operational, tactical, and strategic level implications. Similar to the first phase, we conducted semi-structured interviews and asked each participant to describe their or their key clients' organisational setup and the nature of the decision-making and coordination including planning and monitoring processes, procedures for design and documentation of decisions, and the roles involved. The interview sessions lasted 45-75 minutes, were audio-recorded and transcribed. For our analysis, we integrated all transcripts into the qualitative analysis tool MAXQDA. Inspired by the grounded theory coding process of open-axial-selective coding (Strauss and Corbin, 1991), we then conducted an abductive qualitative analysis (see Table 2).

\begin{tabular}{|c|c|c|c|c|}
\hline Quote & $\begin{array}{c}\text { Code } \\
\text { (Challenge) }\end{array}$ & $\begin{array}{l}\text { Mechanism } \\
\text { (D. Feature) }\end{array}$ & $\begin{array}{l}\text { Requirement } \\
\text { (D. Principle) }\end{array}$ & $\begin{array}{l}\text { Outcome } \\
\text { (D. Goal) }\end{array}$ \\
\hline $\begin{array}{l}\text { “Think about Nokia: from boots to mobiles. There } \\
\text { was a clear decision. [.. ] On corporate level, it may be } \\
\text { similar to the old product, but one level down is total- } \\
\text { ly different. Because you need electronics engineers } \\
\text { and no chemists.” (translated from German) }\end{array}$ & $\begin{array}{l}\text { Strategic fit } \\
\text { internal: Clash } \\
\text { strategic goals, } \\
\text { products, and } \\
\text { skills }\end{array}$ & $\begin{array}{l}\text { Skill mapping } \\
\text { for matching } \\
\text { people to } \\
\text { product }\end{array}$ & \begin{tabular}{|} 
Ensure right \\
people work- \\
ing on right \\
product at \\
right time
\end{tabular} & \multirow{2}{*}{$\begin{array}{c}\text { Alignment } \\
\text { of internal } \\
\text { resources } \\
\text { with exter- } \\
\text { nal de- } \\
\text { mands }\end{array}$} \\
\hline $\begin{array}{l}\text { "You need to follow the market. When I know what } \\
\text { they want, it is like building a house: How do I realize } \\
\text { it? If you have a vision, mission and perhaps a }\end{array}$ & & $\begin{array}{l}\text { Forming ca- } \\
\text { pabilities } \\
\text { along vision } \\
\text { based on cus- } \\
\text { tomer needs }\end{array}$ & \begin{tabular}{|c|} 
Ensure right \\
resources \\
available for \\
fulfilling needs \\
rapidly \\
\end{tabular} & \\
\hline
\end{tabular}

Table 2. $\quad$ Example for analysis process of empirical data.

As a-priori codes, we used Henderson and Venkatraman's (1993) SAM model as the most prominent alignment representation with its strategic (external) and operational (internal) dimension, the individual components, and their links (e.g. strategic fit) to organise challenges and mechanisms for agility in the interviews like e.g. cross-functional teams. Concepts in the transcripts that are not included in the model (e.g., customer journey mapping) were assigned with an open code to signify a potential alignment gap. Via constant comparison within a code area (e.g., 'functional integration internal'), we consolidated the codes by a common character (e.g. collaboration of autonomous teams to achieve alignment across services). For instance, the two codes 'meetings among product teams in 2 weeks for coordination of backlogs' and 'architectural advice for product specification' were consolidated into the single code 'mutual cross-team coordination'. These represent the design features as the general mechanisms for addressing the identified challenges. To attain the final results, we then iteratively continued to consolidate the codes across code areas by commonalities regarding underlying requirements, which resemble the design principles, and subsequently derived aspired outcomes of each requirement as the design goals. Beyond the examples in Table 2, this resulted in codes like 'flexible planning process on all levels for fast configuration' (design principle) or 'outcome-oriented decisions for customer reflection' (design goal).

To improve validity and generalisability (Benbasat and Zmud, 1999), we evaluated the identified challenges, goals, and principles with four experts from different backgrounds: a manager of an agile enterprise, a product owner in another agile company, an experienced agile consultant, and a researcher on agility. The experts provided comprehensive qualitative feedback by breaking down the results' structure, utility, level of completeness and detail, and applicability (Hevner et al., 2004). The results showed that our results are comprehensive and valid, as they cover the main characteristics of agility and the resulting needed changes for alignment. However, revisions such as e.g. refinement of goals' descriptions are required. For instance, one evaluation partner explained that not only do external threats influence the shape of the resulting organisational response on how to cope with the risk, but also the company's aspired business goals are an influencing factor to identify suitable mechanisms. 


\section{$4 \quad$ Challenges, Goals, and Principles for BITA in Agile Contexts}

In this section, we first show that organisations respond differently in the light of agility but have to overcome common alignment challenges. Based on those, we then describe the identified design goals and principles to achieve alignment and agility and show examples of more concrete design features as corresponding mechanisms. These challenges, goals, principles and features then form the foundation for our reconceptualisation of BITA. We follow the recommendations of Meth et al. (2015), Legner and Löhe (2012), and Drechsler and Hevner (2018) concerning the presentation of the goals and principles, with one key difference, however. We formulate design goals instead of requirements as agile contexts are continuously changing themselves, and therefore goals as a representation of long-term aspirations for organisational change are a more suitable concept than requirements which imply that they are to be demonstrably fulfilled by a specific (and static) solution. Table 3 gives an overview based on the identified BITA-related challenges in relation to agility.

\begin{tabular}{|c|c|c|c|}
\hline Challenge & Design Goal & Design Principle & Design Feature (examples) \\
\hline $\begin{array}{l}\text { C1: Establish } \\
\text { an effective } \\
\text { focus on the } \\
\text { relevant busi- } \\
\text { ness environ- } \\
\text { ment(s) }\end{array}$ & $\begin{array}{l}\text { DG1: Understand the eco- } \\
\text { system response alignment } \\
\text { gap: Identification of } \\
\text { threats in the business eco- } \\
\text { system and subsequent re- } \\
\text { quired multi-dimensional } \\
\text { response of the organisation } \\
\text { (addresses C1, C4) }\end{array}$ & $\begin{array}{l}\text { DP1: Understand and expli- } \\
\text { cate the ecosystem: Clarifi- } \\
\text { cation and visualisation of } \\
\text { customer value, needs, and } \\
\text { touchpoints to the organisa- } \\
\text { tion to prepare for fit with } \\
\text { customer and partner needs } \\
\text { (addresses DG1, DG2) } \\
\end{array}$ & \begin{tabular}{|l} 
- Customer value stream \\
(I12, I20) \\
- Partner value stream \\
(FG5, I28) \\
- Customer journey (I3, I29) \\
- Persona (FG1, I27)
\end{tabular} \\
\hline $\begin{array}{l}\text { C2: Balance } \\
\text { local autonomy } \\
\text { concerning the } \\
\text { used IT with } \\
\text { the organisa- } \\
\text { tion-wide opti- } \\
\text { mum }\end{array}$ & $\begin{array}{l}\text { DG2: Foster alignment } \\
\text { between external and in- } \\
\text { ternal value propositions: } \\
\text { Persistent focus on customer } \\
\text { and partner needs instead of } \\
\text { focus on internal affairs } \\
\text { (addresses C1) }\end{array}$ & $\begin{array}{l}\text { DP2: Employ customer vi- } \\
\text { sion-oriented strategic di- } \\
\text { rection: Definition of out- } \\
\text { come-based goals based on } \\
\text { identified current and poten- } \\
\text { tial future customer needs to } \\
\text { ensure fit with them } \\
\text { (addresses DG1, DG2, DG3) } \\
\end{array}$ & $\begin{array}{l}\text { - Enterprise vision (I14, I25) } \\
\text { - Strategic goals (FG5, I18) } \\
\text { - Roadmapping (I2, I29) } \\
\text { - Product vision (I13, I17) }\end{array}$ \\
\hline $\begin{array}{l}\text { C3: Balance } \\
\text { local autonomy } \\
\text { concerning } \\
\text { services and } \\
\text { their function- } \\
\text { alities with the } \\
\text { organisation- } \\
\text { wide optimum } \\
\end{array}$ & $\begin{array}{l}\text { DG3: Enable continuous } \\
\text { (re)alignment: Ongoing fit } \\
\text { between external customer } \\
\text { and partner needs and inter- } \\
\text { nal organisational services, } \\
\text { structures and processes to } \\
\text { fulfil these needs } \\
\text { (addresses C2, C3, C4) } \\
\end{array}$ & $\begin{array}{l}\text { DP3: Align delivery 'struc- } \\
\text { ture' around customer value } \\
\text { flow: Optimal combination of } \\
\text { business and IT capabilities } \\
\text { for frictionless delivery of the } \\
\text { 'right' customer services as } \\
\text { fast as possible } \\
\text { (addresses DG2, DG4) }\end{array}$ & $\begin{array}{l}\text { - Cross functional team (I2, I8) } \\
\text { - Product team (FG6, I12) } \\
\text { - Internal value stream } \\
\text { (FG5, I7) } \\
\text { - Capability mapping (I10, I27) } \\
\text { - Objectives and key results } \\
\text { (OKR) (I1, I17) } \\
\text { - Purpose setting (I11, I25) } \\
\end{array}$ \\
\hline \multirow[t]{2}{*}{$\begin{array}{l}\text { C4: Cope with } \\
\text { the fluidity of } \\
\text { the organisa- } \\
\text { tional structure }\end{array}$} & $\begin{array}{l}\text { DG4: Empower corporate } \\
\text { engagement: } \\
\text { Continuous converged pro- } \\
\text { active involvement of busi- } \\
\text { ness and IT staff } \\
\text { (addresses C2, C3) }\end{array}$ & $\begin{array}{l}\text { DP4: Enable autonomous, } \\
\text { yet informed decision- } \\
\text { making: Information points } \\
\text { for coordinating concerns } \\
\text { regarding services and capa- } \\
\text { bilities within and between } \\
\text { levels } \\
\text { (addresses DG3, DG4) }\end{array}$ & $\begin{array}{l}\text { - Strategic product owner } \\
\text { (I18, I22) } \\
\text { - Open planning room (FG1, I2) } \\
\text { - Open tool access (I10, I28) } \\
\text { - Community of practice } \\
\text { (I6, I12) } \\
\text { - Architectural vision (I5, I20) } \\
\text { - Shared services functions } \\
\text { (I1, I20) }\end{array}$ \\
\hline & & $\begin{array}{l}\text { DP5: Set up a meta- } \\
\text { reorganisation capability: } \\
\text { Continuous information ex- } \\
\text { change and adaptation proce- } \\
\text { dures across organisation } \\
\text { (addresses DG2, DG3) }\end{array}$ & $\begin{array}{l}\text { - Skill to kill (FG1, I23) } \\
\text { - Short cadences (FG2, I26) } \\
\text { - Decentral team planning } \\
\text { (I3, I20) } \\
\text { - Central meta-planning (port- } \\
\text { folio) management (FG3, I6) }\end{array}$ \\
\hline
\end{tabular}

Table 3. Challenges, design goals, principles, and sample features for BITA in agile contexts. 


\subsection{Challenges for BITA in agile contexts}

In this section we identify a set of BITA-related challenges that the participants reported facing.

First, we note that different types of organisations tend to choose different structural configurations for their agile organisational set-ups. Small organisations with a low number of IT personnel compared to IT systems and services and public organisations tend to employ a team-based approach towards agility. These use agile project teams with a stable service owner coming from business, who is responsible for the delivery and improvement of the service, next to the rest of the team which is more fluid. These organisations use projects for continuously balancing their scarce resources or for fulfilling regulatory requirements for change initiatives, as public projects have to be tendered, for instance. In contrast, companies with a B2B focus tend to use the unit-based approach towards agility: a structural bimodal IT setup with digital units, often relying on internal as well as external resources. As FG3 elaborates: "Internal employees have an organisational baggage because of our history. If we want to disrupt existing business models or products, we cannot think with an existing mind-set." While some digital units may still use projects to deliver services, these organisations increasingly switch to stable product teams with an end-to-end responsibility for their services within a specific business or product domain in order to support productivity by combining knowledge and autonomy. Finally, we see that organisations with a B2C focus tend to use the enterprise-wide approach for agile transformation. They also transform towards stable end-to-end product teams but their transformation encompasses the whole of the IT and business organisation. The rationale for these organisations is that they are much closer to the customer than B2B organisations and, thus, are more threatened by market volatility.

Despite these differences in organisational set-ups, we found four common BITA-related challenges in agile transformations among the companies (see Figure 1). Figure 1 distinguishes the team level, unit level, and enterprise level within an organisation. Figure 1 further highlights that - due to the teams' and units' increased autonomy in agile contexts - BITA considerations (represented by the SAM matrix) need to take place independently on each level as well, and also independently for each team and unit, as each element interacts autonomously with their relevant parts of the surrounding ecosystem.

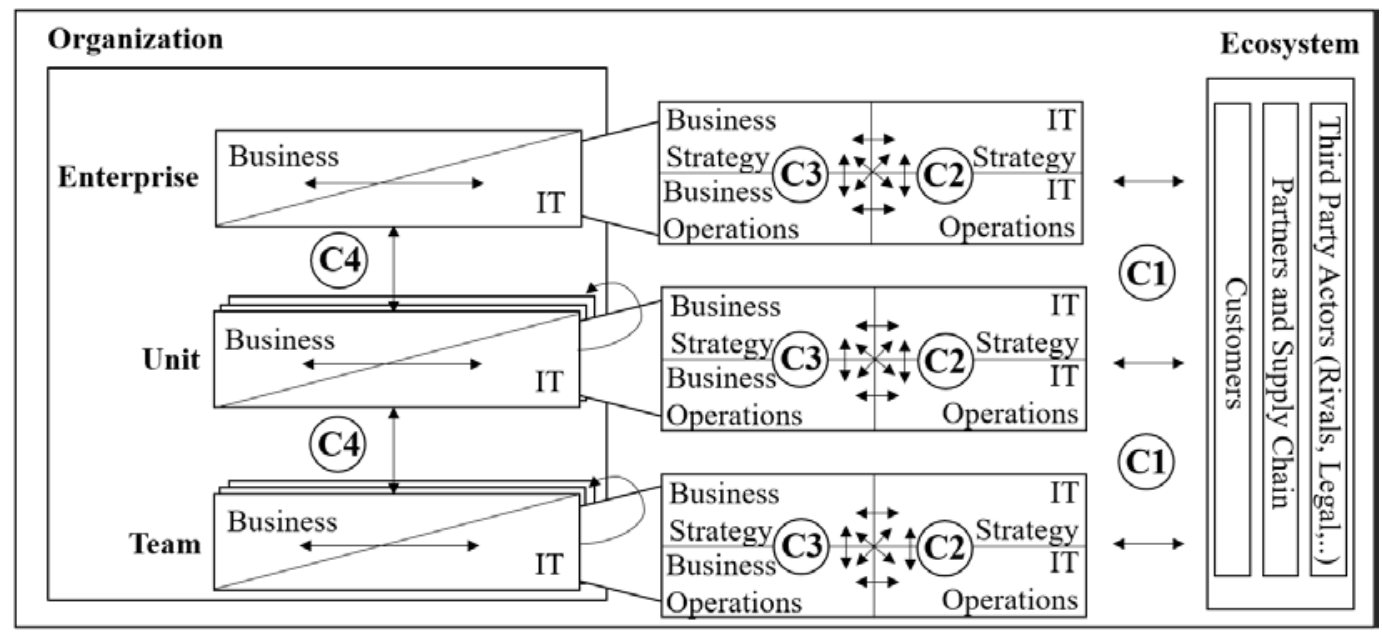

Figure 1. Challenges to Business-IT alignment by agile contexts.

The first common alignment-related challenge among the organisations is to establish an effective focus on the business environment(s) (C1) they are acting in for (fore)seeing changes and subsequently adjusting their products or services. As the actors (customers, partners, and third parties) within the business environment are (in)directly influencing each other in the market, the awareness involves the whole network of the business ecosystem and the subsequent service ecosystem(s) for the organisation's individual products or services.

The two next challenges are balancing the autonomy concerning the used IT (C2) and concerning service functionalities with the organisation-wide optimum (C3). The idea behind autonomy on the 
team and unit level is to facilitate rapid responses to perceived market or product gaps. Yet, as customer products or services usually are composites that involve multiple teams or may have re-usable business or IT components across products or services, there needs to be an active balancing of local concerns for each unit or team with the (hypothetical) global organisation-wide optimum.

The fourth and final challenge for organisations is to cope with the fluidity of the organisation's structure and processes (C4) for enabling a fast response. Traditionally, organisational structures and processes are established as a stable 'arena' for the different units, teams, and individuals within an organisation to work together in an aligned fashion. However, in agile contexts changes to organisational setups are explicitly encouraged, and thus limiting the extent of stability and alignment that they can provide. In this regard, alignment must enable flexibility in the structural setup while simultaneously enabling people to work together as frictionless as possible.

We found all the identified challenges to be addressed by each organisation, but with varying mechanisms. As mechanisms that are effective for one organisation may be not applicable to others, we subsequently take a more abstract view in the form of design goals and principles. To support concretising these abstract considerations, we also show examples of design features implementing the goals and principles in the form of concrete alignment mechanisms that some of the organisations rely on.

\subsection{Design goals for achieving alignment in agile contexts}

Based on the identified challenges, we now derive design goals for achieving alignment in agile contexts. These design goals provide a stable, long-term and high-level orientation for agile organisations.

The first design goal calls for understanding the ecosystem response alignment gap (DG1). This requires identifying the current and potential future threats in the business ecosystem (C1) and defining the internal desired position and business goals, e.g. cost leadership, as their combination defines the degree of criticality and the resulting organisational response, e.g. introducing digital units. The threats in the ecosystem that influence the company's success can range from high-competing markets with a high turnover to improving the position by communication channels with new technology or manifestation of leading market positions. The degree of necessary change is also shaped by the company's position in the ecosystem (e.g., platform provider or participant), distance from the customer (e.g., B2B vs. B2C), or the organisational capabilities (e.g., low or high capacity for change). Understanding the ecosystem alignment gap gives a clear mission on how to evolve the organisation (C4).

Once the underlying problem is understood, actionable response initiatives are required to fill the identified gap by fostering alignment between external and internal value propositions (DG2). First, this is because the picture of the customer has changed: "Traditionally from the IT perspective, we perceived the customer as the people from controlling and marketing. But I always say: No, it is the end customer on the $5^{\text {th }}$ Avenue. [...] It is a total customer and consumer obsession." (FG5) Second, the power shifts to the customer so that companies need to focus on the customer experience more than ever. As many organisations' success is more than ever dependent on fulfilling customer needs, BITA in agile contexts requires extending the traditional alignment notion - which comprised the internal domains of business and IT - by considering the external business ecosystem as well (C1). Since (parts of) the value-creation rely on involvement of business partners, e.g., by (semi)exclusively offering their services on a platform, organisations need to understand any partner needs as well. This requires the alignment also to span the supplier experience to prevent a weakening of the affected parts of the customer value by moving to rivals. Finally, knowing competitors' actions and sensing changes in the organisation's remaining business ecosystem such as regulatory and legal changes are still essential, as they may also indirectly weaken the customer value creation.

With the customer perspective in focus, agility involves the ability of continuously providing customer value (which is now regarded as a moving target) at any time, as "you don't have a start and end anymore, but a continuous lifecycle [of engagement] to consider" (FG5) for being able to embrace changes. Thus, organisations need a continuous (re)alignment ability (DG3). The ability involves two dimensions: (1) continuous re-evaluation of the ecosystem, its needs and the fit of the company and its value creation (external view), and (2) the ability for continuously aligning the organisation in case of 
changing (parts of) the corporate value creation (internal view). When striving for agility, both dimensions are relevant, but presumably to a different extent and with varying alignment mechanisms. The external dimension mainly involves continuously scanning the ecosystem, and whether it still fulfils the customer need to predict movements in the ecosystem relevant for the company (C4). The internal dimension then encompasses the ability to use this information and reconfigure the affected parts of the internal value creation according to the identified change requirements (C2\&3). This refers to the systemic ability for adaptation by swiftly shifting organisational contexts based on changing prerequisites. This requires both a corresponding structural and processual organisational setup to enable smooth changes of resources towards different contexts and change readiness of individuals.

The continuous change involves an active enterprise in order to stay responsive. Thus, we see a final design goal encompassing the ability for a proactive corporate engagement (DG4) to reflect agility's proactive nature. We posit that merely striving to align the different parts of an enterprise is too passive, as both business and IT need to proactively shape the corporate reality (C2\&3). As especially digital services deeply intertwine business and IT logic, continuous business and IT engagement is key for fast and smooth service delivery. As FG5 elaborates: "So if we talk about introducing voice as topic, no one tells me: I am logistics, customer service, HR or IT. No, we are all in this together." Thus, while there will also be support functions in IT and business with a more limited access to the customer, every part of the organisation needs to understand their importance in the value delivery to the customer. Striving for continuous engagement and change also involves the mandate for continuous service innovation, which is a responsibility for both business and technological service optimisation opposing the traditional separation of plan, build and run, as "you have a common goal by business and IT: the customer. There is no blaming of the other." (FG6). Thus, the joint mandate for continuous service innovation involves the engagement of both exploitation of existing ones as well as exploring potentials of new ones to always be "one step ahead" (FG1).

\subsection{Design principles for effective alignment in agile contexts}

In this section, we present design principles for effective alignment in agile contexts that are suitable to fulfilling the previously derived design goals and addressing the challenges for agile organisations.

As agility is a response based on the immense power of customers today, the awareness that customer value creation and the right response to their needs (at the right time) is more than ever directly linked to corporate success or failure. This mind-set requires organisations to be able to understand and explicate the ecosystem (DP1). This mainly involves the explication of the customer, whether internal or external, and the partner value creation following DG1 and DG2, but also addresses a consideration of competitors' moves. We call the overall understanding of the experience by the customer in a specific ecosystem (the 'lifeworld') the customer value stream, which involves all steps that customers partake in value creation overall to see "How do I know how value gets to the customer? What needs to be sort of happening to get the value?" (INT-14). The customer value stream splits into multiple customer journeys that address specific underlying recurring customer problems and the resulting needs such as the need to travel from place A to B. Both dimensions help identifying the 'touchpoints' of the company with its services and the extent that these currently cover to see potential optimisations, e.g. regarding which partner should be integrated and whether services can or should cross different customer journeys to ease customer value stream(s). While information gathering approaches with social interaction and data analyses are unsurprisingly part of this, explication also involves visualisation for awareness within the organisation, e.g. via value stream mapping or personas for customer characterisation. To enable everyone to act in alignment with the goals, making these visualisations accessible to everyone in the organisation is key. Furthermore, the entire endeavour of understanding the ecosystem is an ongoing activity, as changes in the ecosystem may occur at any time.

The biggest change we see within the organisation is not only recognising, but incorporating the mindset of customers as powerful, yet impatient ecosystem participants. Thus, the mind shift of continuously putting the customer in the centre of attention (DG2) starts at the strategic level with a customer need-oriented strategic direction (DP2). Thus, a strategy is depicted as a vision of expected changes 
of customer needs and a set of aspired goals instead of concrete actionable plans. Vision orientation is perceived as essential for aligned agility (DG3), as "a vision is always forward-looking, so that you cannot rest by focusing on your current business model and strategy. [...] You can use hypotheses or goals for it, but basically you need to be constantly challenged, if your ideas are what the customer wants" (INT-23). The strategic goals are derived by customer value creation being continuously mapped to the organisational value proposition(s) within one or multiple existing business models as well as with the underlying business capabilities of the organisation to see where the corporation should move next (DG1). Every initiative then has to show that it contributes to the goals, so that strategic planning artefacts like business cases increasingly include the link to the outcomes as mandatory information. On the unit and team level, most organisations use product visions for contrasting their future roadmap with the needed abilities and metrics (like Objectives and Key Results - OKR) to identify whether a team achieved its goal or not. Strategy now integrates and fuses IT and business planning, essentially removing the need for alignment after their formulation.

Anchoring the entire alignment effort with the ecosystem also needs a new way of thinking for linking the delivery organisation by aligning the delivery 'structure' around the customer value flow (DP3) for limiting potential frictions as much as possible to ensure a high speed of delivery (DG2). One challenge that organisations face regarding their structure is the mismatch between services and the IT architecture. As INT-29 elaborates: "The business side [...] thinks in products. They describe end-to-end the services offered to customers. These are transformed into functional requirements per component, the technical specification. They are handed over to the individual component teams, but those do not see the link. Why do I have to implement a certain feature or change a component? They do not see that it's linked to the end-to-end journey for a customer." Thus, organisations aim for value flow-driven structures to improve the alignment of business and IT, e.g. by establishing crossfunctional feature teams that are end-to-end responsible for a certain customer service and involve all required capabilities for its fast delivery and adaptation. Such teams are embedded in the overall value flow via internal value streams (DG4). They are the counterpart to the customer value stream and journeys and comprise all necessary capabilities for providing a part of a customer value stream and allocate the involved enterprise resources, systems, and information for realising the capabilities.

While a value flow-driven structure enables the alignment between the operational and the strategic perspective in a structural way, it does not enable speed and flexibility in the process per se. Thus, we see that organisations need to enable autonomous, yet informed decision-making (DP 4). Empowering the teams and units to make decisions as local as possible is a common facilitator for agility. Defining the services they deliver as part of a customer product or service requires information exchange to support informed decision-making. By setting up cross-functional teams including all key functions needed to create customer value like marketing, UX, or IT engineers, organisations seek to foster local decision making (DG4). Yet, information from others only enables teams' success, as certain services may require specific capabilities or other services: "[The teams are] are like boy football. Everyone is active, but nobody scores. And that is indeed a problem, as you do not progress that way. That is why we come together." (INT-17) In addition, everyone needs to understand the consequences of their actions. Thus, open and continuous information sharing is a prerequisite, which comprises e.g. the strategic development, product visions and shared concerns like security or architecture. Especially the architecture vision is perceived as critical due it being prone to enforce organisational inertia, as units are optimised for local optima, but not for seeing the global effects by their decisions (DG3). Architectural decisions are made based on discussions and common consent instead of based on authority: "If you've got an architect [and] [...] Chinese whispers start happening, you lose. [...] The ivory tower architects come up with something that people on the ground discover that doesn't work, they don't bother saying anything. They just code around it.” (INT-12). To avoid such a disconnect, prominent practices include common areas for visualising the work, open communities of practice for coordinating specific topics or open tools including information from visions to the single tasks and features.

As the business ecosystem is in flux, we see that a meta-reorganisation capability (DP5) ought to be in place that allows a fast shift in direction and structure while still enabling the frictionless delivery (DG3). The structural flexibility is enabled by teams' and units' outcome orientation so that they can 
be readjusted along a value stream or transferred in an easier way by defining a new purpose (DG2). The ability regarding direction further includes teams' end-to-end responsibility concerning continuous improvement of customer fit with the services. This implies a 'skill to kill' to be able to shift their focus towards new contexts. Although the meta-organisation capability is decentralised, the organisations perceive that a central meta-analysis process is still required. This is often constructed as a value portfolio management process, in which business and IT executives should be equally involved: " $A t$ that level, somebody needs to have an organisational view. The ideal person, that's the CEO and his team, because they should have that big picture of the organisation. [...] I would say that it's another community of practice, but it's working at that highest level. In holacracy, it is your governing circle [...]. They should be looking at the overall structure of the organisation on a regular basis." (INT-12)

\subsection{Towards a revised model of BITA for agile contexts}

In this section, we move beyond agile BITA design goals and principles to reconceptualise BITA for agile contexts. Taken together, the previous findings result in four new alignment dimensions in contrast to the traditional BITA perspective (see Figure 2). First, we propose ecosystem alignment as new dimension to consider the need for continuous fit with the business ecosystem, mainly customers and partners, to realize DP1. Second, we propose that strategic fit rather acts as an enterprise vision alignment to ensure that the customer value aligns the products or services along the common vision following DP2. Third, architectural alignment is required as further dimension for DP3 and DP4, as the capabilities, structures and processes for delivering the services and their business and IT components need a fit with the services and vice versa. In this regard, the SAM's cross-domain alignment on enterprise level becomes the integration between the different visions of customer services and their fit to internal corporate services that they might use. Within each customer service, cross-domain alignment occurs between the sub-services and between the responsible autonomous teams and units as consequence. The traditional functional integration becomes part of the teams or units' mandate to achieve functional convergence, especially when business and IT skills are located within the teams or units. The fourth dimension involves the continuous re-alignment across the organization for being able to adapt to changes in the ecosystem, as depicted in DP5. In sum, our new understanding of alignment is now a continuous and rapid, reactive and proactive (re)fitting and (re)converging of internal business and IT capabilities, structures, and processes across all organizational levels to adjust with, i.e. meet the needs and possibly also influence, the surrounding business ecosystem.

The first dimension of ecosystem alignment is not new per se, at least for customer alignment. Other disciplines like service science have emphasised customer orientation for quite some time, as creating effective offerings involves a co-creation of value by the customer and the organisation (Vargo and Lusch, 2004; Grönroos, 2011) based on their contextual expectations and perceptions. A broad toolbox for explication of the value creation parts 1) customers' value, 2) the reflection of the customer services, and 3) the interaction in-between and their touchpoints does also already exist, e.g. in interaction design with service blueprints, interaction sketches and customer journey maps (Kalbach, 2016). Our research shows that agility involves the service and value logic on both the individual service and the strategic level for being able to adapt to changes in the ecosystem. As organisations are depicted as one big overall service system, similar to service ecosystems (Lusch et al. 2010; Meynhardt et al., 2016; Vargo and Lusch, 2016), this involves the fit of the whole enterprise vision to the customer value creation as customers' needs for the strategic functional integration. Second, ecosystem alignment involves partner alignment, since customer value creation may rely on business partners, e.g., by offering their services (semi) exclusively on a platform. The customer and partner alignment is also to be reflected within each subset, each involving a socio-technical and dynamic value co-creation configuration of resources like information and people (Maglio et al., 2009; Böhmann et al., 2014).

The second dimension of enterprise vision alignment is the equivalent to the traditional strategic fit, but with a different orientation. In contrast to traditional long-term strategic plans targeting the concrete scope and approach of solutions - as most alignment research is focusing on - a shift to a long term outcome-based vision with corresponding adjustable strategic goals shall foster agility, as the 
outcome logic leaves enough freedom. Yet, explicating the end-to-end customer experience and how everyone contributed to it requires mechanisms on all organisational levels to enable this outside-in view. Therefore, alignment in the sense of achieving strategic fit now means actively aligning the internal organisation with the external ecosystem view via the fit of individual visions of products or services with the enterprise vision instead of a mere orientation towards the external dimension of business strategy and business operations (Henderson \& Venkatraman, 1993). Then, the concerns are separated on the service level instead by business or IT via the service vision, which in turn serves as new angle of vision-oriented alignment on team level by providing the input for the purpose and resulting sub-services of the individual team and determine the resulting decisions in their backlogs. For most organisations, a common enterprise vision and strategic goals instead of separate business and IT strategy, similar to the digital business strategy that is increasingly emphasised in research (Preston \& Karahanna, 2009; Bharadwaj et al., 2013; Kahre et al., 2017), is also seen as essential as precondition.

Architectural alignment as the third alignment dimension in agile contexts rather targets the functional integration. Encapsulating each individual team, unit and the enterprise - both regarding the IT direction and the direction of the services they offer to customers (see Figure 2) - shall facilitate speed in delivery as much as possible by socio-technical modularization. However, as the autonomy of each element results in an individual perspective on the understanding of the ecosystem due to its local focus and knowledge creation, the fit within and between the autonomous levels is essential regarding their understanding of the ecosystem, the resulting gap to the customer services and the consequent organisational response. To overcome the locality, architectural alignment is required, which involves two directions. With customer value as overarching architectural element, architectural alignment implies aligning the different parts of a product's or service's entire architecture of capabilities, functionalities (sub-services) and corresponding IT architecture to ensure to deliver the 'right' customer service. This leads to functional convergence by socially merging business and IT capabilities for each sub-service and for each service, e.g. via cross-functional teams. Yet, the horizontal fit across capabilities, functionalities (sub-services) and IT architecture is also essential to ensure a shared understanding between teams. Thus, and in contrast to traditional alignment research (Reich \& Benbasat, 2000), architectural alignment realizes the call for social alignment (Tallon, 2008; Tallon \& Pinsonneault, 2011; Liang et al., 2017) both on the operational and the executive level by creating a social link within and between units and teams based on the customer value.

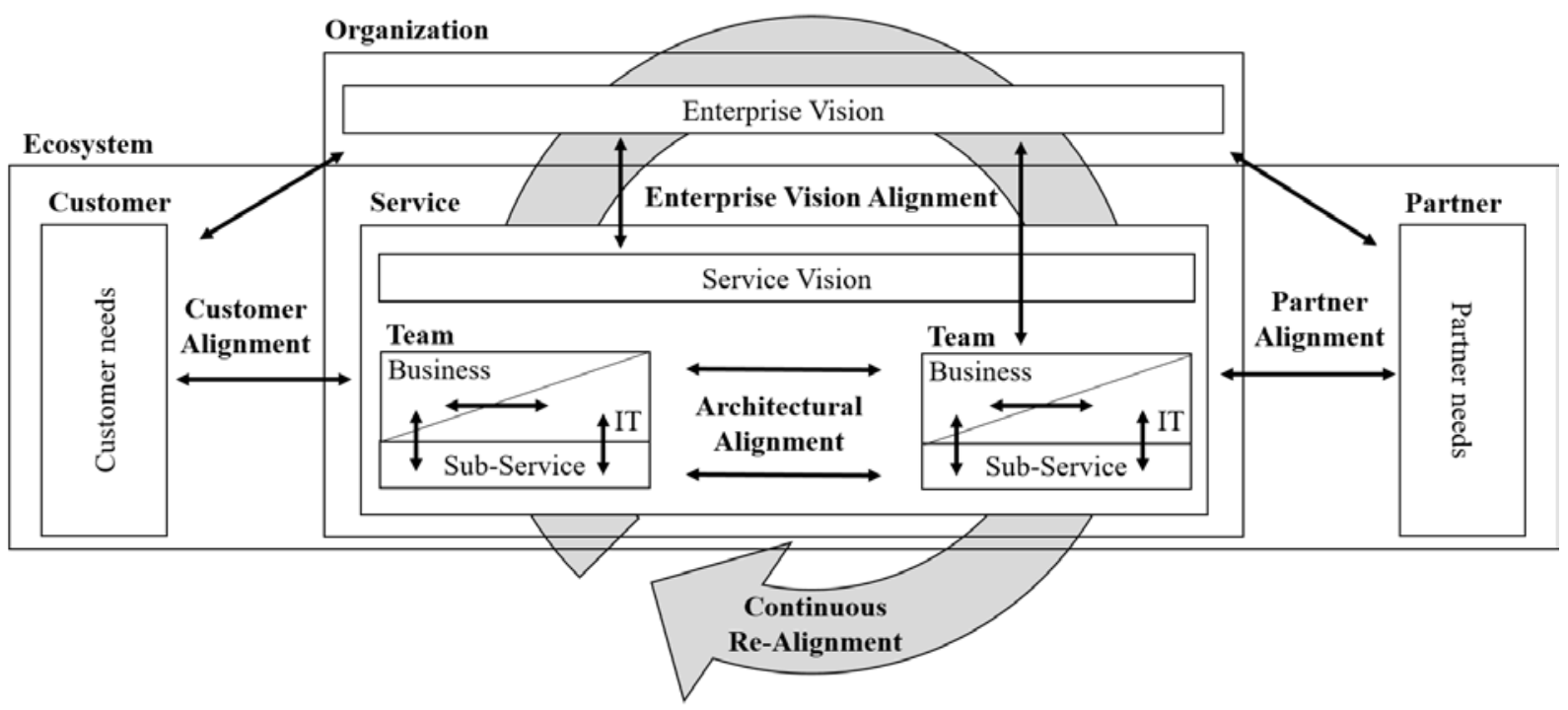

Figure 2. Business-IT alignment model for agile contexts.

Finally, the ongoing consideration of the external view requires a continuous organizational realignment ability in order to adapt to new contexts. As the individual teams continuously gather customer insights, continuity in alignment occurs by continuous cross-organisation fit with short feedback cycles to get a shared understanding and revaluate the fit of value within and across customer services. 
In turn, this results in 1) the 'right' services, as the units use the external needs as driving force instead of internal interests and 2) the flexibilisation of underlying business processes and IT architecture by enabling an adaptive strategic fit by translating value into processes and architectures (Henderson \& Venkatraman, 1993). Thus, continuous re-alignment involves the optimization of the offered services, the service structure in terms of its functionalities as well as the continuous re-evaluation of the involved capabilities. In this regard, organizations continuously strive to achieve optimal internal capabilities through a continuous resource (re-)allocation and tailoring (e.g. people, skills and IT architecture) in order to provide the best possible service - but without ever reaching a stable optimum.

\section{$5 \quad$ Discussion and Conclusion}

Based on an exploratory study with a multitude of business and IT professionals and experienced consultants in the agile field, we contribute four BITA-related challenges (answering RQ1), four design goals and five design principles to address these challenges (answering RQ2), and a reconceptualisation of BITA itself for agile contexts (answering RQ3): First, alignment in agile contexts is not only about the internal fit of the different parts of the organisations but also encompasses a much closer connection to the surrounding business ecosystem. Second, we show that alignment in agile contexts is primarily concerned with the architectural fit of all of a product's or service's components, in order to allow the organisation to be highly responsive to changing ecosystem needs. Architectural alignment supersedes the alignment of business and IT functions, as the latter may not even exist at all in some organisational setups due to structural convergence and common strategies. Moreover, our BITA reconceptualisation places a stronger emphasis on continuous external as well as internal changes and places therefore a greater emphasis on continuous (re)alignment on all levels.

Of course, our research is not without limitations. Although we base our research on a multitude of roles involved in organisations striving for agility or conducting consulting work for such companies, we did by far not cover all business and IT perspectives. Especially support functions, which are merely indirectly affected by the changing ecosystem needs and the resulting organisational adjustments, are missing in our view. As these functions are also rarely the focus of research on BITA next to their yet missing analysis in relation to agility, we encourage further studies in order to gain a more comprehensive view, especially concerning how these support functions contribute value to the other organisational parts in the best way to achieve agility and how they should be aligned in the overall context in order to not create new frictions. We also do not cover the strategic perspective from the business side. Although some of the interviewed CIOs are part of the corporate executive board, more insights regarding a strategic fit is required. This needs in-depth analysis of the strategic development and execution process of corporations that are transforming to highly responsive enterprises. The insights would also contribute missing knowledge in regard to agility on the strategic level, which is often depicted as a black box by research and the scaling agile frameworks.

A second limitation is the conceptual nature of our findings. Although we aim to cover a broad spectrum of different industries, organisational sizes and the resulting organisational responses with our design goals and principles, our results require verification by additional studies. Therefore, we encourage further research on the underlying differences between the organisational responses like large scale agile companies. This would especially support a better understanding on the first design goals of identifying the right response for the individual alignment gap and help creating more in-depth recommendation on which approach should be fostered for the individual situation. While we see some patterns in this regard, a more profound analysis of contingency factors would gain more detailed insights. Finally, we encourage to extend our insights on alignment and agility with detailed analyses on specific alignment dimensions, as these are missing by large extent in the academic debate. While this applies for the 'right' structural and strategic alignment at the moment, we perceive that inquiries are particularly required concerning achieving a cultural alignment within the organisation. Many organisations are currently in the transition stage and explore different mechanisms for achieving agility in their structure, processes and strategies. However, as "culture eats strategy for breakfast", the cultural alignment will be crucial for sustaining alignment in the long run. 


\section{References}

Baskerville, R. L., Kaul, M., and V. C. Storey (2015). "Genres of Inquiry in Design-Science Research: Justification and Evaluation of Knowledge Production." MIS Quarterly 39 (3), 541-564.

Beck, K., Beedle, M., van Bennekum, A., Cockburn, A., Cunningham, W., Fowler, M., Grenning, J., Highsmith, J., Hunt, A., Jeffries, R., Kern, J., Marick, B., Martin, R. C., Mellor, S., Schwaber, K., Sutherland, J. and D. Thomas (2001). Agile Manifesto. URL: http://agilemanifesto.org/principles. html (visited on 10/11/2019).

Benbasat, I. and R. W. Zmud (1999). "Empirical Research in Information Systems: The Practice of Relevance.” MIS Quarterly 23 (1), 3-16.

Bharadwaj, A., El Sawy, O. A., Pavlou, P. A. and N. Venkatraman (2013). "Digital Business Strategy: Toward a Next Generation of Insights.” MIS Quarterly 37 (2), 471-482.

Böhmann, T., Leimeister, J. M. and K. Möslein (2014). "Service Systems Engineering: A Field for Future Information Systems Research.” Business Information Systems Engineering 6 (2), 73-79.

Bradley, R. V., Pratt, R. M. E., Byrd, T. A., Outlay, C. N. and D. E. Wynn (2012). "Enterprise Architecture, IT Effectiveness and the Mediating Role of IT Alignment in U.S. Hospitals." Information Systems Journal 22 (2), 97-127.

Broadbent, M., Weill, P., and B. S. Neo (1999). "Strategic Context and Patterns of IT Infrastructure Capability.” Journal of Strategic Information Systems 8 (2), 157-187.

Chan, Y. E. (2002). "Why Haven’t We Mastered Alignment? The Importance of the Informal Organization Structure.” MIS Quarterly Executive 1 (2), 97-112.

Chan, Y. E. and B. H. Reich (2007). "IT Alignment: What Have We Learned?” Journal of Information Technology 22 (4), 297-315.

Conboy, K. and B. Fitzgerald (2004). "Toward a Conceptual Framework of Agile Methods: A Study of Agility in Different Disciplines.” In: Proceedings of the 2004 ACM Workshop on Interdisciplinary Software Engineering Research (WISER). Newport Beach, USA, 37-44.

Denning, S. (2010). "Rethinking the Organization: Leadership for Game-Changing Innovation." Strategy \& Leadership 38 (5), 13-19.

Denning, S. (2016). “Agile’s Ten Implementation Challenges.” Strategy \& Leadership 44 (5), 15-20.

Denning, S. (2017a). "Strategic Agility. Using Agile Teams to Explore Opportunities for MarketCreating Innovation.” Strategy \& Leadership 45 (3), 3-9.

Denning, S. (2017b). “The Next Frontier for Agile: Strategic Management.” Strategy \& Leadership 45 (2), 12-18.

Disciplined Agile (2019). The Disciplined Agile (DA) Framework. URL: http://www.disciplinedagiledelivery.com/ (visited on 13/11/2019).

Doz, Y. and M. Kosonen (2010). "Embedding Strategic Agility: A Leadership Agenda for Accelerating Business Model Renewal.” Long Range Planning 4 (2), 370-382.

Drechsler, A. and A. R. Hevner (2018). "Utilizing, Producing, and Contributing Design Knowledge in DSR Projects.” In: Proceedings of the 13th International Conference on Design Science Research in Information Systems and Technology (DESRIST). Ed. by S. Chatterjee, K. Dutta and R. Sundarraj. Cham: Springer, 82-97.

Faraj, S. and Y. Xiao (2006). "Coordination in Fast-Response Organizations.” Management Science 52 (8), 1155-1169.

Fink, L. and S. Neumann (2009). "Exploring the Perceived Business Value of the Flexibility Enabled by Information Technology Infrastructure.” Information \& Management 46 (2), 90-99.

Fitzgerald, B. and K. -J. Stol (2017). "Continuous Software Engineering. A Roadmap and Agenda." Journal of Systems and Software 123, 176-189.

Gerow, J. E., Grover, V., Thatcher, J. B., and P. L. Roth (2014). "Looking Toward the Future of ITBusiness Strategic Alignment Through the Past: A Meta-Analysis.” MIS Quarterly 38 (4), 10591085. 
Goldman, S. L., Preiss, K. and R. N. Nagel (1995). Agile Competitors and Virtual Organizations: Strategies for Enriching the Customer. 1st Edition. New York: Van Nostrand Reinhold.

Gregor, S. and D. Jones (2007). "The Anatomy of a Design Theory.” Journal of the Association for Information Systems 8 (5), 312-335.

Grönroos, C. (2011). "Value Co-Creation in Service Logic: A Critical Analysis.” Marketing Theory 11 (3), 279-301.

Haffke, I., Kalgovas, B. and A. Benlian (2017a). “Options for Transforming the IT Function Using Bimodal IT.” MIS Quarterly Executive 16 (2), 101-120.

Haffke, I., Kalgovas, B. and A. Benlian (2017b). "The Transformative Role of Bimodal IT in an Era of Digital Business.” In: Proceedings of the 50th Hawaii International Conference on System Sciences (HICSS). Hawaii, USA, 5460-5469.

Haki, M. K. and M. W. Forte (2010). "Proposal of a Service Oriented Architecture Governance Model to Serve as a Practical Framework for Business-IT Alignment.” Proceedings of NISS.

He, Z. L. and P.-K. Wong (2004). "Exploration vs. Exploitation: An Empirical Test of the Ambidexterity Hypothesis.” Organization Science 15 (4), 481-494.

Henderson, J. C. and N. Venkatraman (1993). "Strategic Alignment: Leveraging Information Technology for Transforming Organizations.” IBM Systems Journal 32 (1), 4-16.

Hevner, A. R., March, S. T. and J. Park (2004). "Design Science in Information Systems Research.” MIS Quarterly 28 (1), 75-106.

Hoffmann, D., Mueller, T. and F. Ahlemann (2017). "Balancing Alignment, Adaptivity, and Effectiveness: Design Principles for Sustainable IT Project Portfolio Management.“ In: Proceedings of the 25th European Conference on Information Systems (ECIS). Guimarães, Portugal, 1503-1520.

Horlach, B., Drews, P., Schirmer, I. and T. Böhmann (2017). "Increasing the Agility of IT Delivery: Five Types of Bimodal IT Organization.” In: Proceedings of the 50th Hawaii International Conference on System Sciences (HICSS). Hawaii, USA, 5420-5429.

Horlach, B., Schirmer, I. and P. Drews (2019). "Agile Portfolio Management: Design Goals and Principles.” In: Proceedings of the 27th European Conference on Information Systems (ECIS). Stockholm-Uppsala, Sweden, 1-17.

Kahre, C., Hoffmann, D., and F. Ahlemann (2017). "Beyond Business-IT Alignment- Digital Business Strategies as a Paradigmatic Shift: A Review and Research Agenda.” In: Proceedings of the $50^{\text {th }}$ Hawaii International Conference on System Sciences (HICSS). Hawaii, USA, 1-10.

Kalbach, J. (2016). Mapping Experiences: A Guide to Creating Value through Journeys, Blueprints, and Diagrams. 1st Edition. Farnham: O’Reilly UK Ltd.

Kashanchi, R. and J. Toland (2008). "Investigating the Social Dimension of Alignment: Focusing on Communication and Knowledge Sharing.” In: Proceedings of the 19th Australasian Conference on Information Systems (ACIS). Christchurch, New Zealand, 462-471.

Kearns, G. S. and A. L. Lederer (2003). "A Resource-Based View of Strategic IT Alignment: How Knowledge Sharing Creates Competitive Advantage.” Decision Sciences 34 (1), 1-29.

Kim, G., Humble, J., Debois, P., and J. Willis (2016). The DevOps Handbook: How to Create Worldclass Agility, Reliability, and Security in Technology Organizations, 1st Edition, Portland: IT Revolution Press.

King, W. R. (1978). “Strategic Planning for Management Information Systems.” MIS Quarterly 2 (1), 27-37.

Kniberg, H. and A. Ivarsson (2012). Scaling Agile at Spotify. URL: http://blog.crisp.se/2012/11/14/henrikkniberg/scaling-agile-at-spotify (visited on 12/11/ 2019).

Krueger, R. A. and M. A. Casey (2014). Focus Groups: A Practical Guide for Applied Research. 1st Edition. Thousand Oaks: SAGE Publications.

Kuechler, W., and V. Vaishnavi, V (2008). "The Emergence of Design Science Research in Information Systems in North America.” Journal of Design Research 7 (1), 1-16.

Laanti, M. and M. Kangas (2015). "Is Agile Portfolio Management Following the Principles of LargeScale Agile? Case Study in Finnish Broadcasting Company Yle.” In: Proceedings of the 2015 Agile Conference (AGILE). Washington, D.C., USA, 92-96. 
LeSS Company (2019). Large Scale Agile Scrum (LeSS). URL: https://less.works/ (visited on 14/11/2019).

Lederer, A. L. and A. L. Mendelow (1989). "Coordination of Information Systems Plans with Business Plans.” Journal of Management Information Systems 6 (2), 5-19.

Lee, O.-K. D., Sambamurthy, V., Lim, K. H. and K. K. Wei (2015). "How Does IT Ambidexterity Impact Organizational Agility.” Information Systems Research 26 (2), 398-417.

Liang, H., Wang, N., Xue, Y. and Ge, S. (2017). "Unraveling the Alignment Paradox. How Does Business-IT Alignment Shape Organizational Agility?” Information Systems Research 28 (4), 863-879.

Lu, Y. and K. Ramamurthy (2011). "Understanding the Link Between Information Technology Capability and Organizational Agility: An Empirical Examination.” MIS Quarterly 35 (4), 931-954.

Luftman, J., Papp, R. and T. Brier (1999). "Enablers and Inhibitors of Business-IT Alignment.” Communications of the Association for Information Systems 1 (11), 1-33.

Luftman, J., Lyytinen, K. and T. Ben Zvi (2017). "Enhancing the Measurement of Information Technology Business Alignment and Its Influence on Company Performance.” Journal of Information Technology 32 (1), 26-46.

Lusch, R. F., Vargo, S. L. and M. Tanniru (2010). “Service, Value Networks and Learning.” Journal of the Academy of Marketing Science 38, 19-31.

Maglio, P. P., Vargo, S. L., Caswell, N. and J. Spohrer (2009). "The Service System Is the Basic Abstraction of Service Science.” Information Systems and e-Business Management 7 (4), 395-406.

Melarkode, A., From-Poulsen, M. and S. Warnakulasuriya (2004). "Delivering Agility through IT." Business Strategy Review 15 (3), 45-50.

Meth, H., Mueller, B. and A. Maedche (2015). “Designing a Requirement Mining System.” Journal of the Association for Information Systems 16 (9), 799-837.

Meynhardt, T., Chandler, J. D. and P. Strathoff (2016). "Systemic Principles of Value Co-Creation: Synergetics of Value and Service Ecosystems." Journal of Business Research 69 (8), 2981-2989.

Moe, N. B., Dahl, B., Stray, V., Karlsen, L. S. and S. Schjødt-Osmo (2019). "Team Autonomy in Large-Scale Agile.” In: Proceedings of the 52nd Hawaii International Conference on System Sciences (HICSS). Hawaii, USA, 6998-7006.

Overby, E., Bharadwaj, A. and V. Sambamurthy (2006). "Enterprise Agility and the Enabling Role of Information Technology.” European Journal of Information Systems 15 (2), 120-131.

Paasivaara, M. and C. Lassenius. (2014). "Communities of Practice in a Large Distributed Agile Software Development Organization-Case Ericsson." Information and Software Technology 56 (12), 1556-1577.

Preston, D. S. and E. Karahanna (2009). "Antecedents of IS Strategic Alignment: A Nomological Network.” Information Systems Research 20 (2), 159-179.

Pyburn, P. J. (1983). "Linking the MIS Plan with Corporate Strategy-An Exploratory Study.” MIS Quarterly 7 (2), 1-14.

Reich, B. H. and I. Benbasat (2000). "Factors that Influence the Social Dimension of Alignment between Business and Information Technology Objectives.” MIS Quarterly 24 (1), 81-113.

Roberts, N. and V. Grover (2012). "Leveraging Information Technology Infrastructure to Facilitate a Firm's Customer Agility and Competitive Activity. An Empirical Investigation.” Journal of Management Information Systems 28 (4), 231-270.

Sambamurthy, V., Bharadwaj, A. and V. Grover (2003). "Shaping Agility through Digital Options: Reconceptualizing the Role of Information Technology in Contemporary Firms.” MIS Quarterly 27 (2), 237-263.

Scaled Agile (2019). Scaled Agile Framework. URL: http://www.scaledagileframework.com/ (visited on 15/11/2019).

Schwaber, K. and J. Sutherland (2019). The Scrum Guide. URL: https://www.scrumguides.org/ (visited on 10/11/2019).

Sherehiy, B., Karwowski, W. and J. K. Layer (2007). "A Review of Enterprise Agility: Concepts, Frameworks and Indicators.” International Journal of Industrial Ergonomics 37 (5), 445-460. 
Smith, W. K. (2014). "Dynamic Decision Making: A Model of Senior Leaders Managing Strategic Paradoxes.” Academy of Management Journal 57 (6), 1592-1623.

Strauss, A. L. and J. M. Corbin (1991). Basics of Qualitative Research: Grounded Theory Procedures and Techniques. 1st Edition. Newbury Park: SAGE Publications.

Sushil (2015). "Strategic Flexibility: The Evolving Paradigm of Strategic Management." Global Journal of Flexible Systems Management 16 (2), 113-114.

Tallon, P. P. (2008). "A Process-Oriented Perspective on the Alignment of Information Technology and Business Strategy.” Journal of Management Information Systems 24 (3), 227-268.

Tallon, P. P. and A. Pinsonneault (2011). "Competing Perspectives on the Link between Strategic Information Technology Alignment and Organizational Agility: Insights from a Mediation Model.” MIS Quarterly 35 (2), 463-484.

Tiwana, A. and S. K. Kim (2015). "Discriminating IT Governance.” Information Systems Research 26 (4), 656-674.

Tiwana, A. and B. Konsynski (2010). "Complementarities between Organizational IT Architecture and Governance Structure.” Information Systems Research 21 (2), 288-304.

Ullah, A. and R. Lai (2013). "A Systematic Review of Business and Information Technology Alignment.” ACM Transactions on Management Information Systems 4 (1), 1-30.

Van Der Zee, J. T. M. and B. De Jong (1999). "Alignment is Not Enough: Integrating Business and Information Technology Management with the Balanced Business Scoreboard.” Journal of Management Information Systems 16 (2), 137-156.

Van Oosterhout, M., Waarts, E. and J. van Hillegersberg (2006). "Change Factors Requiring Agility and Implications for IT.” European Journal of Information Systems 15 (2), 132-145.

Vargo, S.L. and R. F. Lusch (2004). "Evolving to a New Dominant Logic for Marketing.” Journal of Marketing 68 (1), 1-17.

Vargo, S. L., and R. F. Lusch (2016). "Institutions and Axioms: An Extension and Update of ServiceDominant Logic." Journal of the Academy of Marketing Science 44 (1), 5-23.

VersionOne (2019). 13th Annual State of the Agile Report. URL: https://www.stateofagile.com/ (visited on $12 / 11 / 2019)$.

Vessey, I. and K. Ward (2013). "The Dynamics of Sustainable IS Alignment: The Case for IS Adaptability.” Journal of the Association for Information Systems 14 (6), 283-311.

Weick, K.E. (1995). "What Theory is Not, Theorizing Is.” Administrative Science Quarterly 40 (3), 385-390.

XSCALE Alliance (2018). XSCALE. URL: http://xscalealliance.org/ (visited on 10/11/2019). 